\title{
O PERFIL DO GESTOR DA INFORMAÇÃO: UM ESTUDO A PARTIR DOS EGRESSOS DO CURSO DE GESTÃO DA INFORMAÇÃO DA UFPE
}

\author{
PERFIL DEL GESTOR DE INFORMACIÓN: UN ESTUDIO \\ DE LOS GRADUADOS DEL CURSO DE GESTIÓN DE LA \\ INFORMACIÓN UFPE
}

\author{
Tatyane Lucia Cruz* \\ Fábio Mascarenhas e Silva** \\ Leilah Santiago Bufrem*** \\ Natanael Vitor Sobral ${ }^{* * *}$
}

\begin{abstract}
RESUMO:
Introdução: Com as recentes transformações sociais e econômicas, surgiram novas possibilidades de atuação dos profissionais da informação. Neste contexto, insere-se o Gestor da informação, que pode contribuir na busca de soluções para os principais desafios relativos à coleta, processamento e uso da informação. Objetivo: Identificar as convergências e divergências entre a formação acadêmica do gestor da informação, egresso da UFPE, em relação à sua atuação profissional. Metodologia: a) revisão bibliográfica; b) mapeamento dos egressos; c) elaboração do questionário; d) disponibilização do questionário; e) tabulação e formatação dos dados; f) análise dos dados. Resultados: 54 dos 71 egressos responderam o questionário (76\%), percentual considerado satisfatório. Destacam-se os seguintes resultados: $85 \%$ dos egressos estão desenvolvendo atividades profissionais; $56 \%$ dos ocupados estão atuando em atividades relacionadas à área de Gestão da Informação; os segmentos de atuação profissional são diversos, com destaque para o setor de serviços (34\%). Na pirâmide organizacional, constatou-se que o nível de atuação mais representativo é o operacional $(43 \%)$. No quesito disciplinas, chamou a atenção que os gestores têm uma maior necessidade de empregar os conhecimentos ligados a Tecnologia da Informação. Conclusões: Ressalta-se a importância do Gestor da informação na

*Mestranda em Ciência da Informação pelo Programa de Pós-Graduação em Ciência da Informação da Universidade Federal de Pernambuco (UFPE). E-mail: tatyanelcruz@gmail.com **Doutor em Ciência da Informação pelo Programa de Pós-Graduação em Ciência da Informação da Universidade de São Paulo (USP). Docente do Programa de Pós-Graduação em Ciência da Informação da Universidade Federal de Pernambuco (UFPE). E-mail:

fabiomascarenhas@gmail.com

***Doutora em Ciências da Comunicação pela Universidade de São Paulo. Docente do

Programa de Pós-Graduação em Ciência da Informação da Universidade Federal de

Pernambuco (UFPE). E-mail: santiagobufrem@gmail.com

****Doutorando em Ciência da Informação pelo Programa de Pós-Graduação em Ciência da Informação da Universidade Federal da Bahia (UFBA). E-mail: natan_sobral@yahoo.com.br
\end{abstract}


Tatyane Lucia Cruz. Fábio Mascarenhas e Silva. Leilah Santiago Bufrem. Natanael Vitor Sobral.

O perfil do gestor da informação: um estudo a partir dos egressos do curso de Gestão da Informação da UFPE

atualidade, enfatizando a necessidade de aperfeiçoamento dessa profissão recente em relação às demandas da sociedade.

Palavras-chave: Atuação profissional. Formação. Gestor da informação. Gestão da informação. UFPE.

\section{INTRODUÇÃO}

A humanidade vivenciou transformações que modificaram a forma de se produzir bens e riquezas. Para Lastres e Ferraz (1999), estas transformações modificaram o arranjo da economia global, tais como os ativos geradores de riqueza, os países reconhecidos como líderes ou em desenvolvimento, a infraestrutura, e os setores propulsores do crescimento.

Na base desta estrutura, há ativos que impulsionam a produção e são determinantes na configuração da ordem econômica mundial, tais como o carvão, o minério, o petróleo e a informação. Independente da fase histórica, a informação e o conhecimento se revelaram presentes, desde as primeiras interações do homem com a natureza, numa relação de constructo cultural que culminou na descoberta do fogo, no domínio das técnicas agrícolas, no aprimoramento das técnicas de exploração do minério e até mesmo na consecução das transformações tecnológicas, como as mais recentes, advindas das Tecnologias da Informação (TI).

$\mathrm{Na}$ atual era das conexões digitais e das empresas em rede, muitos processos empresariais se tornaram obsoletos frente ao novo desafio trazido pelo universo digital. Vivenciam-se os correios eletrônicos, os negócios digitais, as mídias sociais, as transações financeiras virtuais, os relacionamentos corporativos eletrônicos entre as empresas e clientes, dentre outros procedimentos culturais marcados pelas transformações dos modos de produção.

A principal repercussão causada pelo contexto supracitado é o crescimento da produção de informações nos ambientes interno e externo das organizações. Em relação ao aspecto material, tratam-se de informações sobre registros de transações, comportamentos dos clientes, pesquisas sobre o negócio, produtividade dos colaboradores, acervos documentais, material 
Tatyane Lucia Cruz. Fábio Mascarenhas e Silva. Leilah Santiago Bufrem. Natanael Vitor Sobral.

O perfil do gestor da informação: um estudo a partir dos egressos do curso de Gestão da Informação da UFPE

bibliográfico, grau de maturação dos projetos, aceitação de novos produtos e serviços e relatórios de desempenho das empresas. Numa perspectiva imaterial, são informações de rumores de mercado, clima organizacional, concorrentes, expectativa dos clientes de melhoria ou desenvolvimento de novos produtos e serviços, entre outras.

Ao passo em que estas mudanças sociais e empresariais ocorrem, cresce a demanda por profissionais aptos a atuarem com comportamentos, atitudes e conhecimentos condizentes com as demandas atuais das organizações. Conforme indica Marchiori (2002), em um mundo cada vez mais requisitante de modelos e procedimentos voltados à estruturação de conteúdos informativos, profissionais com alta capacidade de gerenciamento e habilidades de mediação são necessários.

Neste contexto, percebe-se a inserção do profissional Gestor da informação, que pode contribuir na busca de soluções para os principais desafios relativos à coleta, ao processamento e ao uso da informação, reforçando o papel de destaque da informação nos contextos público e privados.

Diante destas mudanças, o papel dos agentes formadores - como as universidades por meio dos cursos de graduação - impõe-se como um caminho institucional para contemplar a sociedade com recursos humanos que atuem nesta zona de interesse. Ademais, admite-se que os modelos formativos atuais na área de informação têm se demonstrado insuficientes para suprir a grande complexidade relativa aos contextos informacionais. Assim, constatados os elementos circunstanciais e condicionantes visíveis na conjuntura desse universo, pode-se afirmar, conforme concepção de Bourdieu (1983), que se tem um novo "campo científico" e profissional, caracterizado por relativa autonomia na sociedade, tanto pela sua estrutura, quanto pelas suas relações econômicas, políticas e sociais. Reconhecida a estrutura de demandas, possibilidades, prioridades e restrições nas práticas informacionais, destacamse os componentes motivacionais de um novo profissional, que tanto incorpora valores, quanto expectativas oriundas das condições práticas para sua atuação. 
Tatyane Lucia Cruz. Fábio Mascarenhas e Silva. Leilah Santiago Bufrem. Natanael Vitor Sobral.

O perfil do gestor da informação: um estudo a partir dos egressos do curso de Gestão da Informação da UFPE

Uma formação em nível superior impôs-se pela sua possibilidade de agregar conhecimentos que possibilitem ao profissional atuar criticamente na intersecção entre as áreas de Ciência da Informação $(\mathrm{Cl})$, Administração e Tl, superando as condições dadas e movida pelo desejo de impulsionar os resultados das organizações através do uso estratégico da informação.

Neste sentido, a Universidade Federal de Pernambuco (UFPE) iniciou o curso de graduação em Gestão da Informação $(\mathrm{Gl})^{1}$ no início do ano de 2009 , com o intuito de contribuir para a formação de profissionais adequados à atual conjuntura da sociedade. Esta graduação busca suprir uma nova demanda de profissionais, capazes de interagir e agregar valores nos processos de geração, transferência e uso da informação e na documentação no campo de gestão do conhecimento (UNIVERSIDADE FEDERAL DE PERNAMBUCO, 2012).

A problemática desta pesquisa compõe-se de questões sobre as percepções dos egressos do curso de Gl, tendo em vista se tratar de uma formação relativamente nova, carente de estudos que apresentem um panorama da atuação no mercado de trabalho dos recentes egressos desta área. Outro aspecto decorrente do pequeno tempo de formação do curso é a inexistência de um referencial que indique se a formação da graduação está alinhada aos principais desafios surgidos no mercado de atuação profissional, em especial, na Região Metropolitana do Recife (RMR), onde o curso em análise é ofertado.

A partir dessas premissas, desenvolveu-se a seguinte questão a ser respondida neste trabalho: a atuação dos gestores da informação no mercado de trabalho está alinhada ao perfil almejado no Projeto Político Pedagógico (PPP) do curso de graduação em Gestão da Informação da UFPE?

Sendo assim, o objetivo deste trabalho é identificar as convergências e divergências entre a formação acadêmica do gestor da informação em relação

\footnotetext{
${ }^{1}$ A UFPE possui também um curso de MBA em Gestão da Informação oferecido Departamento de Engenharia de Produção, que já formou mais de 200 profissionais, e existe desde o ano de 2001. Site: http://www.dep.org.br/cursos/index.php?curso=3
} 
Tatyane Lucia Cruz. Fábio Mascarenhas e Silva. Leilah Santiago Bufrem. Natanael Vitor Sobral.

O perfil do gestor da informação: um estudo a partir dos egressos do curso de Gestão da Informação da UFPE

à atuação profissional. Assume-se que o acompanhamento dos egressos desta graduação se apresenta como um relevante instrumento para avaliar a contribuição do curso para a sociedade, avaliar a configuração dos espaços de atuação, mapear as prováveis oportunidades de melhoria na formação, além de possibilitar o prognóstico de uma linha de comportamento futuro desta profissão, mediante a realidade atual que foi registrada.

\section{REFERENCIAL TEÓRICO}

O referencial analisado constituiu-se a partir das construções teóricas sobre: a formação profissional e o trabalho; o profissional de Gl e o Curso de Graduação em GI na UFPE. Esse referencial oferece elementos de análise dos dados resultantes da pesquisa. Com essa fundamentação, pretende-se identificar elementos que possam favorecer a análise relacionada às convergências e divergências entre a formação acadêmica do gestor da informação em relação à atuação profissional.

\subsection{Formação Profissional e o Trabalho}

A partir da década de 1960, a relação entre a formação profissional e o mercado de trabalho passou a ser entendida como algo não meramente ornamental, mas decisiva para o desenvolvimento econômico (SAVIANI, 2003). Embora o vínculo estreito entre trabalho e educação tenha suas bases na antiguidade, conforme afirma Gondim (2002), o surgimento das primeiras propriedades privadas permitiu a ascensão de uma classe ociosa, sustentada por trabalhos executados pela grande massa, iniciando-se assim uma nova forma de educação, mais focada na formação de lideranças políticas e militares, não se restringindo ao aprendizado necessário para se incluir no sistema produtivo.

Aos poucos, a educação foi se tornando cada vez mais o elemento central para o desenvolvimento de civilizações, sendo o lastro mais digno para as pessoas saírem da miséria econômica a partir da transformação intelectual e da qualificação técnica e profissional. Atualmente, as relações entre a 
Tatyane Lucia Cruz. Fábio Mascarenhas e Silva. Leilah Santiago Bufrem. Natanael Vitor Sobral.

O perfil do gestor da informação: um estudo a partir dos egressos do curso de Gestão da Informação da UFPE

educação e o trabalho são temas recorrentes na pauta dos governos, que buscam incessantemente aferir os resultados decorrentes desta interação, para entender se os setores público e privado estão sendo atendidos em suas necessidades de recursos humanos.

Neste sistema, os investimentos de longo prazo das empresas e do governo desempenham uma função importante na definição das necessidades futuras de formação e qualificação profissional (BRASIL, 2012). O contexto social, o desenvolvimento de setores emergentes, a consolidação de setores tradicionais e as expectativas de investimentos em novos negócios formam a base das demandas estratégicas de formação de novos perfis profissionais adequados a estas realidades. Desta maneira, a noção de formar profissionalmente está sempre associada à absorção deste contingente de formados por algum segmento produtivo da sociedade que os acolherá, a atividade que exercerão e a instituição que contribuirá para sua formação.

Importa salientar a concepção equivocada de formação absorvida por teorias educacionais voltadas ao pragmatismo pedagógico como alternativa rápida e eficiente para formação, assim como a defesa da aprendizagem espontânea, pela qual é mais relevante aprender a aprender do que realmente aprender os conteúdos historicamente produzidos.

Por se constituir em processo de devir humano, a formação faz parte da transformação e evolução do indivíduo crítico e capaz de alterar a sua realidade. Neste trabalho, adota-se como conceito de formação o tipo de educação que envolve a formação geral, o estudo de tecnologias e ciências, bem como a aquisição de habilidades práticas, atitudes, compreensão e conhecimentos relacionados com ocupações em vários setores da vida econômica e social, visando preparar pessoas para o mercado de trabalho (ZAPAROLLI, 2004).

No Brasil, a evolução da educação centrada no trabalho está elencada em momentos vividos pelo país a partir da industrialização na década de 1940, a expansão desta fase por volta de 1970, e a sua consolidação em meados de 1990. Neste momento ocorre uma estreita ligação entre o desenvolvimento da formação profissional com o desenvolvimento da indústria capitalista no Brasil. 
Tatyane Lucia Cruz. Fábio Mascarenhas e Silva. Leilah Santiago Bufrem. Natanael Vitor Sobral.

O perfil do gestor da informação: um estudo a partir dos egressos do curso de Gestão da Informação da UFPE

Neste sentido, "a hegemonia, além de expressar uma reforma econômica, assume as feições de uma reforma intelectual e moral." (KUENZER, 1985, p. 52). Como resultado, nasce a privatização da educação profissional no país, e a implementação de cursos sequenciais em universidades (LOURENÇO, 1999).

Carvalhal (2002, p. 41), ao contribuir com esta discussão, afirma que: "a educação, a formação profissional, enquanto esferas constitutivas do ser social, não se reduzem ao trabalho, porém têm nele seu momento fundante, daí o caráter ontológico do trabalho em nossa sociedade [...]". Assim, defendese que a formação é permeada por um espectro de elementos que vão além de uma prática tecnicista, fortalecendo o homem e alterando a sua capacidade de transformar o universo, de modo crítico, analítico e criativo. Um sujeito além da execução, um artesão de conhecimentos.

Essa concepção coincide com a de Kuenzer (2003), de incorporar todas as dimensões educativas que ocorrem no âmbito das relações sociais em prol da formação, ou seja, as dimensões social, política e produtiva, o que implica reconhecer que cada sociedade, em cada modo de produção e regimes de acumulação, dispõe de formas próprias de educação que correspondem às demandas de cada grupo e das funções que lhes cabe desempenhar na divisão social e técnica do trabalho. Desse modo, o desempenho não se restringe ao caráter produtivo, mas abrange todas as dimensões comportamentais, ideológicas e normativas que Ihe são próprias, elaborando a escola sua proposta pedagógica com base em demandas sociais.

Corroborando com isto, Silva e Cunha (2002) argumentam que nesta conjuntura, em que a mudança tecnológica é a regra, buscar condições para ancorar a preparação do profissional do futuro requer uma estratégia diferenciada. Seu valor no mercado será estimado com base em seu dinamismo, em sua criatividade e empreendedorismo. Em especial, quando se trata de uma formação de nível superior, que tem nas Tecnologias da Informação e Comunicação (TIC) as suas principais ferramentas de trabalho. 
Tatyane Lucia Cruz. Fábio Mascarenhas e Silva. Leilah Santiago Bufrem. Natanael Vitor Sobral.

O perfil do gestor da informação: um estudo a partir dos egressos do curso de Gestão da Informação da UFPE

\subsection{O Profissional de GI}

Os modos como a informação é produzida, comunicada, compartilhada, e utilizada, acarretaram mudanças nas relações humanas, de tal maneira que se convencionou chamar a sociedade atual de "sociedade do conhecimento", a qual, na concepção de González de Gómez (1997) agrega novas amplitudes à inteligência humana, mudando assim a maneira de viver e trabalhar em sociedade.

Conforme argumentam Silva e Cunha (2002), graças a essas transformações, é possível processar, armazenar, recuperar e comunicar a informação em qualquer formato, sem interferência de fatores como distância, tempo ou volume. Todavia, a tarefa de gerenciar as informações adequadamente ainda é motivo de preocupação para as empresas que não dispõem de recursos humanos capacitados para planejar, conceber e monitorar sistemas de informação eletrônicos - ou não - que possam dinamizar o uso da informação, favorecendo processos decisórios.

Dessa maneira, a formação do profissional gestor da informação deve pautar-se em competências que façam sentido aos atuais problemas informacionais vivenciados pelas empresas, pois como afirmam Silva e Cunha (2002), o diploma não é garantia de trabalho. Assim, a empregabilidade está relacionada à qualificação pessoal; as competências técnicas deverão estar associadas à capacidade de decisão, de adaptação a novas situações, de comunicação oral e escrita, de trabalho em equipe. O profissional será valorizado na medida em que a sua habilidade de estabelecer relações e liderar se sobressaiam.

Diante deste desafio, a graduação em GI, tem por objetivo formar um profissional capaz de lidar com os diferentes formatos de informação, os inúmeros contextos informacionais, e atender aos diversos usuários de informação existentes. Esse profissional, com perfil analítico e adaptativo, é classificado, segundo Drucker (2015), como um "trabalhador do conhecimento". Esse perfil vai ao encontro do propósito do curso de GI, ou seja, atender às necessidades de modernização do quadro de formação profissional detectadas no mercado de trabalho, no que tange às modernas e dinâmicas expressões da 
Tatyane Lucia Cruz. Fábio Mascarenhas e Silva. Leilah Santiago Bufrem. Natanael Vitor Sobral.

O perfil do gestor da informação: um estudo a partir dos egressos do curso de Gestão da Informação da UFPE

indústria da sociedade da informação (UNIVERSIDADE FEDERAL DE PERNAMBUCO, 2012).

A característica geral deste profissional enquadra-se no que defendem Freire e Araújo (1999): exercitar a responsabilidade social de ajudar a facilitar a comunicação do conhecimento para aqueles que dele necessitam, considerando que esta visão transcende a estrutura organizacional e comunicacional, operada nos Sistemas de Informação.

A GI, enquanto um campo de estudo, tendo em vista sua característica aplicada, tem nos autores que criaram um vínculo estreito com o mercado profissional as suas principais bases teóricas. Um exemplo é Thomas Davenport (1998), que traz uma das definições mais conhecidas sobre o que é a GI: um conjunto estruturado de atividades, que incluem o modo como as empresas obtêm, distribuem e usam a informação e o conhecimento.

Ferreira e Santos (2000) contribuem com essa discussão, acrescentando que este processo requer a intervenção de um coordenador, ou gerente, pois abrange um conjunto de clientes cujas necessidades informacionais devem ser sanadas. Para atender tal expectativa, é preciso que o profissional de GI seja um profundo conhecedor das fontes de informação e dos modos de apresentação preferenciais do grupo de usuários que deseja atender, pois a informação comporta um elemento de sentido, como ressalta Le Coadic (2004), e tal sentido só é passível de compreensão pelo usuário, enquanto pela atribuição de significado a essa informação no mundo que o cerca. A informação pode ser compreendida, desse modo, como o processo de atribuição de sentidos que se dá na mente do usuário.

\subsection{O Curso de Graduação em GI na UFPE}

A aprovação do curso de graduação em GI pelo Conselho Coordenador de Ensino, Pesquisa e Extensão da UFPE (CCEPE/UFPE) ocorreu em abril de 2008. A primeira turma foi iniciada no primeiro semestre de 2009 e, desde então, o curso prossegue rigorosamente no cumprimento de sua responsabilidade de formar profissionais capacitados para atender e atuar no mercado de trabalho na área de GI. 
Tatyane Lucia Cruz. Fábio Mascarenhas e Silva. Leilah Santiago Bufrem. Natanael Vitor Sobral.

O perfil do gestor da informação: um estudo a partir dos egressos do curso de Gestão da Informação da UFPE

O curso é vinculado ao Departamento de Ciência da Informação da UFPE (DCI/UFPE), do Centro de Artes e Comunicação da UFPE (CAC/UFPE) no campus do Recife. A formação ofertada em Gl desenvolve-se em sete períodos consecutivos e presenciais, em que, após a conclusão e aprovação em todos os componentes curriculares obrigatórios, denominada integralização dos créditos, é concedido o grau de Bacharel em Gl ao formando concluinte.

Os quadros 1 e 2 apresentam a estrutura curricular da graduação em GI, exibindo os seus componentes curriculares obrigatórios. O primeiro quadro apresenta os componentes do ciclo básico e, o segundo, as disciplinas do ciclo profissional.

Quadro 1 - Componentes Curriculares Obrigatórios do Ciclo Básico do Curso de GI (UFPE)

\section{COMPONENTES OBRIGATÓRIOS}

\section{- Ciclo Básico}

Fundamentos da Gestão da Informação

Introdução à Organização da Informação

Recuperação da Informação

Metodologia do Trabalho Científico

Teoria Geral da Informação

Direito da Informação

Gestão de Sistemas de Informação

Representação Descritiva da Informação

Fontes de Informação

Fonte: Projeto Político Pedagógico do Curso de GI (UFPE) (2012).

Quadro 2 - Componentes Curriculares Obrigatórios do Ciclo Profissional do Curso de GI (UFPE)

\section{COMPONENTES OBRIGATÓRIOS}

Ciclo Profissional

Fundamentos da Gestão do Conhecimento

Sistemas de Apoio à Decisão

Projeto de Sistemas de Informação

Base de Dados Especializados

Produção e uso da Informação

Indexação e Análise de Assunto

Recursos para Organização da Informação

Introdução aos Recursos de Programação e Sistemas Operacionais

Pesquisa em Ciência da Informação

Estruturas e linguagens da informação

Práticas em Organização da Informação

Formatos e Protocolos de Sistemas

Uso Social da Informação 
Tatyane Lucia Cruz. Fábio Mascarenhas e Silva. Leilah Santiago Bufrem. Natanael Vitor Sobral.

O perfil do gestor da informação: um estudo a partir dos egressos do curso de Gestão da Informação da UFPE

\begin{tabular}{l}
\hline Gestão da Qualidade Total \\
Sistemas de Informação Digital \\
Estudos Métricos da Informação \\
Análise de Decisão \\
Estratégia das Organizações \\
Gestão da Informação nas Organizações \\
Preservação Digital \\
Usabilidade e Arquitetura da Informação \\
Estágio Supervisionado \\
Práticas em Gestão da Informação \\
Seminários Interdisciplinares \\
Trabalho de Conclusão de Curso 1 \\
Trabalho de Conclusão de Curso 2 \\
\hline onte: Projeto Político Pedagógico do Curso de Gl (UFPE) (2012).
\end{tabular}

A estrutura da formação do profissional de GI reúne conhecimentos básicos das áreas de Administração, $\mathrm{Cl}$ e TI, tendo em vista que este deverá atuar em campos dinâmicos, nos quais a informação se faz presente nas mais diversas tipologias, formatos, protocolos, sistemas e usuários. Segundo o PPC do curso de GI da UFPE, o que se espera do egresso é que seja um profissional capaz de interagir e agregar valor aos processos de geração, transferência e uso da informação. Este profissional de postura ativa deve estar apto para atuar em distintos ambientes organizacionais, consciente da importância da informação para os empreendimentos, produtos e serviços de informação. O trabalho do gestor da informação deverá contribuir, consequentemente, para o desenvolvimento socioeconômico, político e cultural da humanidade, acompanhando suas transformações.

\section{PROCEDIMENTOS METODOLÓGICOS}

Nesta pesquisa, foram analisados aspectos relativos à atuação do profissional gestor da informação, na busca de soluções para os principais desafios de sua área, diante do atual contexto e das transformações recentes na Gestão da Informação. Para fundamentar as análises, estudaram-se as construções teóricas sobre a formação profissional e o trabalho; o profissional de Gl; e o curso de graduação em Gl da UFPE. A partir desse estudo, selecionaram-se os elementos constituintes da problemática para que mais 
Tatyane Lucia Cruz. Fábio Mascarenhas e Silva. Leilah Santiago Bufrem. Natanael Vitor Sobral.

O perfil do gestor da informação: um estudo a partir dos egressos do curso de Gestão da Informação da UFPE

precisamente se definissem o problema e suas principais características. Em seguida, passou-se à pesquisa de campo, pela qual foram obtidos os dados, posteriormente submetidos aos processos de análise e interpretação.

Considerando-se que o principal objetivo deste estudo foi constatar se a formação acadêmica do GI egresso da UFPE está alinhada a sua atuação profissional, realizaram-se as seguintes etapas:

a) revisão da literatura, com o objetivo de esclarecer os principais conceitos inerentes ao tema e consolidar conhecimentos para a compreensão das transformações nas atividades do profissional da informação;

b) mapeamento dos egressos, pelo qual se buscou identificar junto à Coordenação do Curso de Gestão da Informação os alunos egressos do curso, desde a primeira colação de grau ocorrida, até os formados em 2015.1;

c) elaboração do questionário, instrumento da pesquisa de campo que apresentou dez questões, sendo uma aberta e nove fechadas (Apêndice A);

d) disponibilização do questionário, submetido anteriormente a um pré-teste, aplicado em cinco alunos concluintes do curso de $\mathrm{GI}$, do qual resultaram ajustes para a construção de sua versão final. Ao final da pesquisa, de um total de 71 egressos, obtiveram-se as respostas de 54, correspondendo a $76 \%$, um número considerado satisfatório;

e) tabulação e formatação dos dados, operações para as quais se contou com a utilização da ferramenta Microsoft Excel para a compilação e geração de gráficos;

f) análise dos dados, pela qual foi possível interpretar os resultados, descrevendo criticamente as relações entre a formação profissional do gestor da informação e a sua prática profissional. Nesta etapa, também foi possível fazer algumas inferências e suposições relacionando os resultados à literatura científica para que se chegasse às considerações finais.

As variáveis sobre os egressos do curso de GI da UFPE consideradas na pesquisa foram as seguintes: ano de formação; titulação complementar; condição mercadológica; localização da atuação; nível organizacional de atuação; segmento institucional de atuação; relevância das disciplinas na rotina de trabalho; relação entre as competências indicadas no PPC com as 
Tatyane Lucia Cruz. Fábio Mascarenhas e Silva. Leilah Santiago Bufrem. Natanael Vitor Sobral.

O perfil do gestor da informação: um estudo a partir dos egressos do curso de Gestão da Informação da UFPE

atividades de trabalho dos egressos do curso de GI/UFPE; e atitudes requisitadas nas atividades de trabalho. Tais dados relacionados permitiram a elaboração das conclusões do artigo.

\section{RESULTADOS E ANÁLISES}

A figura 1 apresenta o total de alunos formados por semestre/ano. Percebe-se que o número de formandos é crescente, possivelmente indicando: a) a retenção - alunos que poderiam ter se formado anteriormente caso seguissem a periodização das disciplinas por semestre, todavia, por razões distintas, o fizeram de maneira atrasada nas turmas subsequentes, contribuindo para a elevação do número de formandos nos últimos semestres; b) maior interesse para concluir o curso - as experiências compartilhadas pelos pioneiros das primeiras turmas possivelmente motivaram os demais alunos a se formarem. Os dois fatores contribuíram para a crescente oferta de gestores para o mercado de trabalho.

Figura 1 - Profissionais formados em GI na UFPE por período/ano

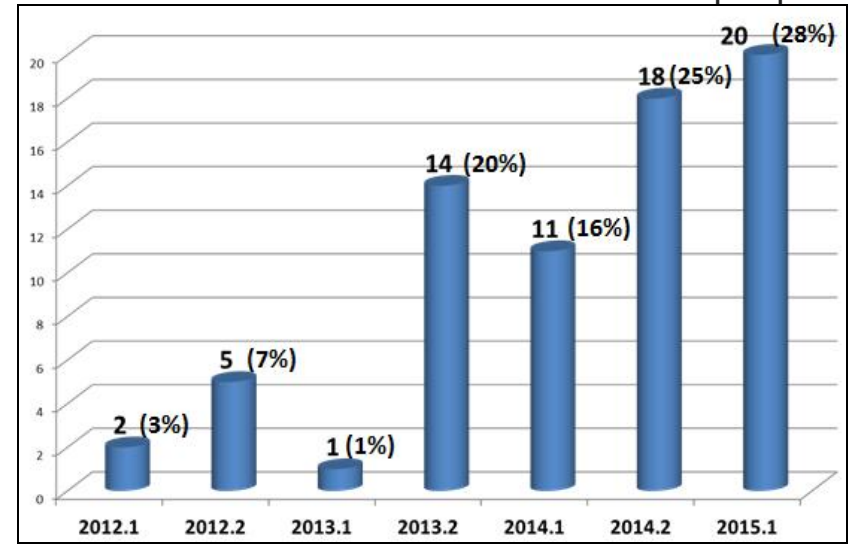

Fonte: Dados da pesquisa, 2017 - Elaboração Própria.

A figura 2 revela as outras formações dos egressos do curso de GI, demonstrando que: $37 \%$ têm outra graduação; 32\% fizeram cursos técnicos ou de tecnólogo; 19\% concluíram uma especialização e 12\% cursaram mestrado. Há casos em que um único gestor tem formação técnica/tecnológica, especialização e mestrado. A soma de formações tende a facilitar a inserção 
Tatyane Lucia Cruz. Fábio Mascarenhas e Silva. Leilah Santiago Bufrem. Natanael Vitor Sobral.

O perfil do gestor da informação: um estudo a partir dos egressos do curso de Gestão da Informação da UFPE

destes profissionais no mercado de trabalho, de maneira que conhecimentos da GI são aliados aos fundamentos de outras disciplinas, coordenados entre si e articulados com as diversas iniciativas, de modo a construir organicidade entre as diversas ações concretas que realizam.

Figura 2 - Titulações complementares dos egressos do curso de GI/UFPE

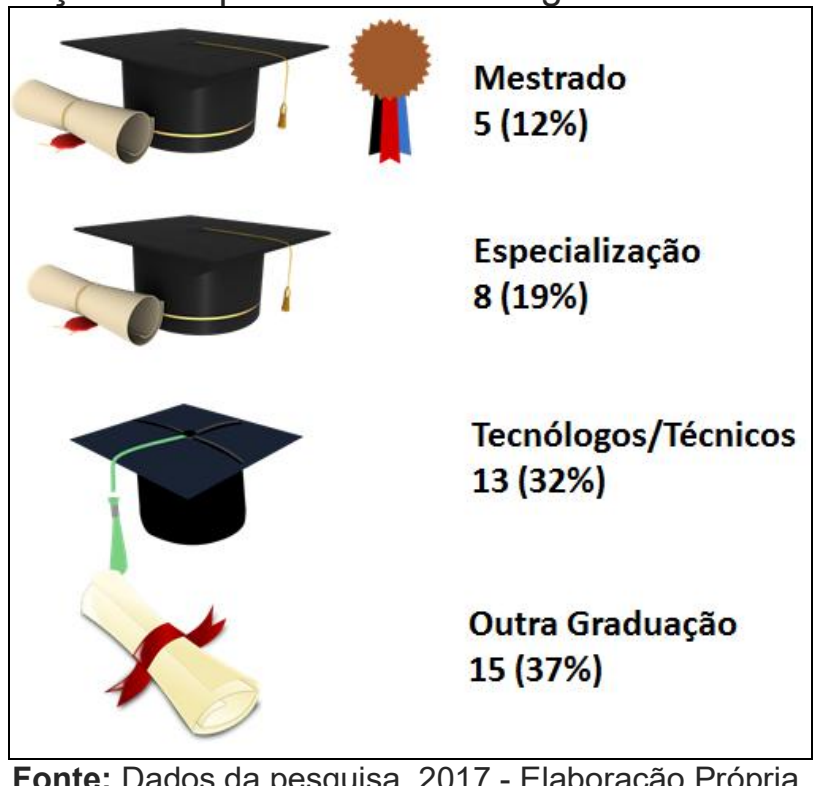

No terceiro tópico (ver figura 3), avaliou-se o lócus de atuação dos egressos. Verificou-se que $48 \%$ consideram atuar em áreas afins à GI (o equivalente a $56 \%$ dos ocupados), enquanto $37 \%$ consideram atuar em atividades relativas a outras funções. Supõe-se que parte destes profissionais ingressou no curso de Gl atuando em áreas que se mantiveram as mesmas quando responderam o questionário. Salienta-se que o fato de o curso de GI ser noturno possibilita que alunos inseridos no mercado de trabalho possam cursá-lo. 
Tatyane Lucia Cruz. Fábio Mascarenhas e Silva. Leilah Santiago Bufrem. Natanael Vitor Sobral.

O perfil do gestor da informação: um estudo a partir dos egressos do curso de Gestão da Informação da UFPE

Figura 3 - Gestores da Informação e sua atuação condição mercadológica.

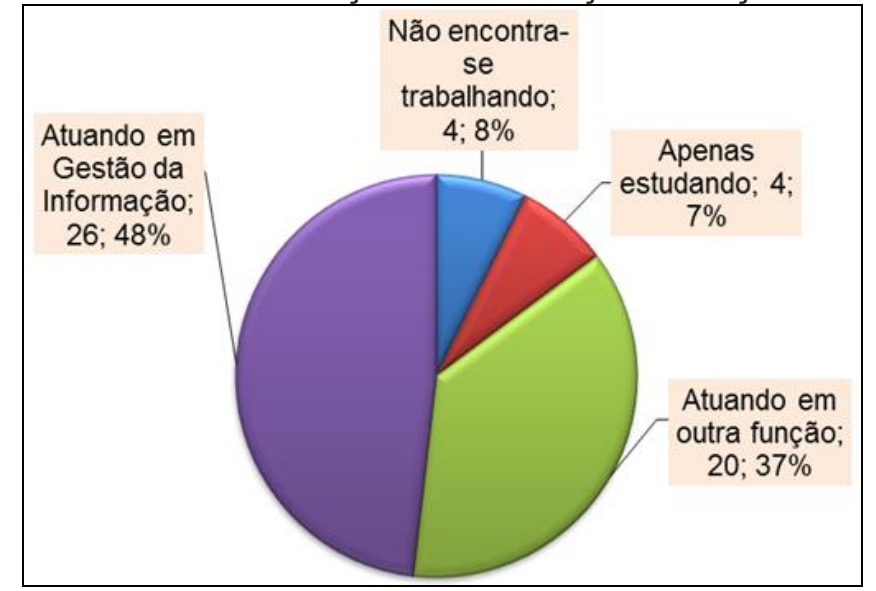

Fonte: Dados da pesquisa, 2017 - Elaboração Própria.

Mesmo os gestores que não atuam na área de GI têm a oportunidade de aplicar conhecimentos aprendidos ao longo da graduação em seus ambientes de trabalho, tendo em vista que os conceitos, as técnicas, os métodos e as ferramentas assimilados na sua formação em GI são úteis nos segmentos em que atuam, independentemente do papel ou cargo.

Dos respondentes que não estão empregados, identificou-se que três eram mestrandos do Programa de Pós-Graduação em Ciência da Informação da UFPE (mestrado acadêmico).

No quarto item, o objetivo foi medir o alcance geográfico da atuação dos alunos egressos do curso de GI. Na figura 4, percebe-se que apenas 9\% dos profissionais analisados atuam fora da RMR. Este dado revela que a formação tem satisfeito uma demanda local, que absorve a mão-de-obra formada, indicando relativo limite de atuação geográfica. Todavia, observando-se pelo ângulo inverso, constata-se que a presença de alunos atuando fora da RMR em tão pouco tempo de curso é um dado positivo e significativo. 
Tatyane Lucia Cruz. Fábio Mascarenhas e Silva. Leilah Santiago Bufrem. Natanael Vitor Sobral.

O perfil do gestor da informação: um estudo a partir dos egressos do curso de Gestão da Informação da UFPE

Figura 4 - Profissionais por localização de atuação

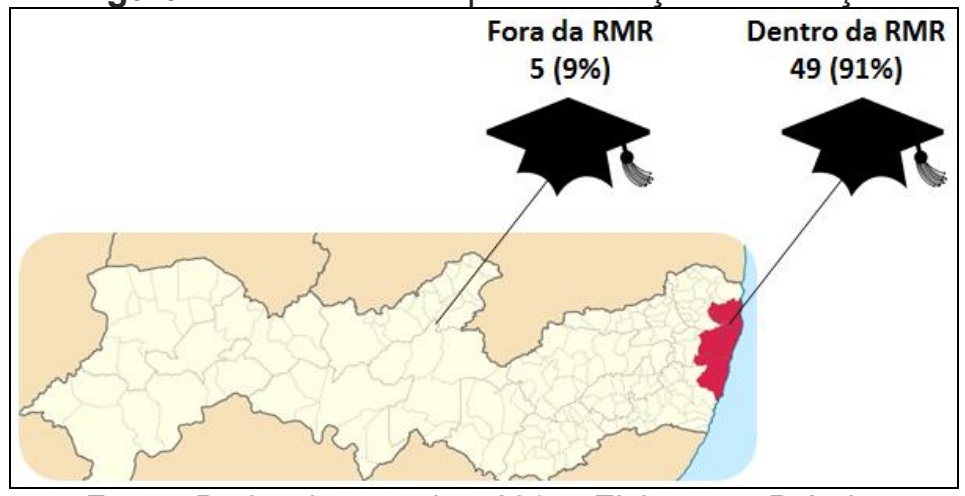

Fonte: Dados da pesquisa, 2017 - Elaboração Própria.

(c) Crédito das imagens: Acervo do Wikimedia Commons (adaptado - uso não comercial)

Em 2016 existem quatro cursos de graduação em GI no Brasil, a saber: Universidade Federal do Paraná (UFPR), UFPE, Universidade Federal de Uberlândia (UFU) e Universidade Federal de Goiás (UFG), respectivamente por ano de fundação. Assim, essas quatro instituições são responsáveis por suprir parcialmente a demanda nacional, atualmente provida também por outros profissionais da informação (bibliotecários, documentalistas, arquivistas, cientistas da informação e informáticos) e por profissionais de outras áreas que desenvolveram por meio de formação complementar ou experiências a competência para atuar na área de GI.

O quinto tópico (figura 5) procurou avaliar a esfera de atuação do egresso, buscando-se compreender, na pirâmide organizacional, em qual estrato os profissionais estavam atuando.

Figura 5 - Inserção dos profissionais por esferas organizacionais

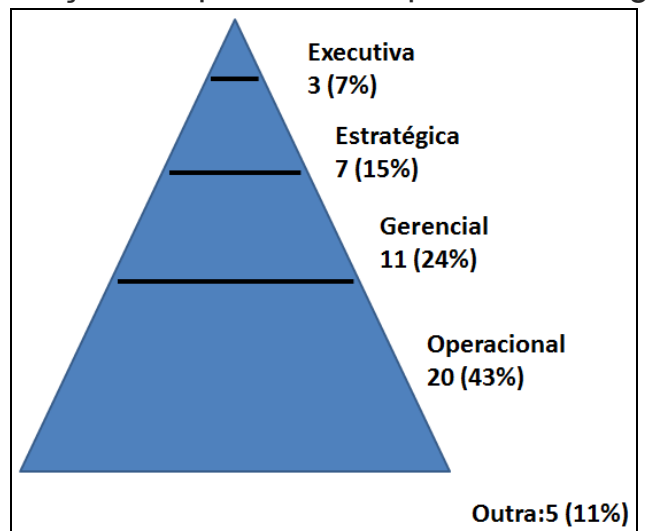

Fonte: Dados da pesquisa, 2017 - Elaboração Própria. 
Tatyane Lucia Cruz. Fábio Mascarenhas e Silva. Leilah Santiago Bufrem. Natanael Vitor Sobral.

O perfil do gestor da informação: um estudo a partir dos egressos do curso de Gestão da Informação da UFPE

É predominante a esfera operacional (43\%), ficando a gerencial em segundo lugar (24\%). Sobre isso, deve-se ponderar que os novos gestores ainda precisam de maior tempo de atuação em suas respectivas instituições, a fim de irem demonstrado o quão qualificados estão para assumirem postos de gestão, comumente ocupados por profissionais com maior vivência e experiência em determinados setores.

A seguir, buscou-se conhecer o segmento das instituições em que os egressos estão atuando (figura 6). Para isto, foram utilizadas as categorias da Classificação Nacional de Atividades Econômicas do Instituto Brasileiro de Geografia e Estatística / Comissão Nacional de Classificação (IBGE/CONCLA).

Figura 6 - Segmentos das instituições de atuação dos egressos de GI/UFPE

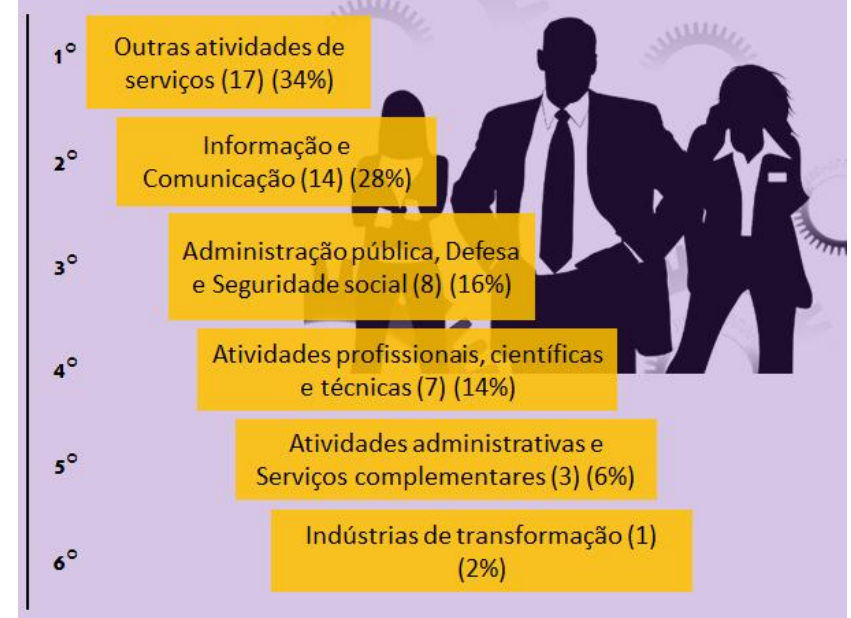

Fonte: Dados do CNAE - Elaboração Própria (2017)².

Identificou-se que 34\% atuam em empresas ligadas ao setor de serviços. Tal circunstância coaduna com o fato de a cidade do Recife ter uma economia reconhecidamente suportada pela área de serviços, conforme aponta um estudo que revela que $41,9 \%$ da economia da cidade concentram-se no setor de serviços ${ }^{3}$.

O segundo comportamento que chama a atenção refere-se ao quantitativo de $28 \%$ dos egressos vinculados às empresas do setor de

2 Os 4 egressos que que se encontram apenas estudando também indicaram o setor de atuação (estágio ou outra atividade relacionada)

${ }^{3}$ http://www2.recife.pe.gov.br/pagina/estrutura-produtiva-do-recife 
Tatyane Lucia Cruz. Fábio Mascarenhas e Silva. Leilah Santiago Bufrem. Natanael Vitor Sobral.

O perfil do gestor da informação: um estudo a partir dos egressos do curso de Gestão da Informação da UFPE

Informação e Comunicação. Pela própria natureza do segmento, é natural a absorção do profissional gestor, tendo em vista o seu viés de atuação estar ligado às TIC. Soma-se a essa circunstância, o fato de que Recife concentra um dos maiores polos tecnológicos do Brasil, o Porto Digital ${ }^{4}$, apontado pela AT Kearney em 2005 como o maior polo tecnológico do país em número de empresas e faturamento (ORENGO; ABREU, 2009), mantendo-se em franca expansão até os dias de hoje, com 250 empresas, 7.100 trabalhadores e 3 incubadoras (PORTO DIGITAL, 2016).

Dos $16 \%$ gestores da informação atuantes em instituições públicas, admite-se que estes não exercem efetivamente a função, sobretudo em razão das autarquias públicas não disporem ainda deste cargo em seus quadros de servidores. Contudo, acredita-se que a inserção desses gestores da informação no segmento público tende a favorecer o reconhecimento e a respectiva inserção destes na agenda do setor público. Seria uma nova concepção de competência, segundo Kuenzer (2003, p. 17), traduzida na capacidade de agir, com agilidade e eficiência, em situações previstas e não previstas, por meio da articulação de conhecimentos tácitos e científicos às "experiências de vida e laborais vivenciadas ao longo das histórias de vida".

Sobre estes novos espaços, Fraser-Arnott (2017) afirma que ao profissional da informação faz-se necessário expandir suas competências em contextos tradicionais para incluir aspectos de gerenciamento de registros, gerenciamento de informações e gerenciamento de conhecimento. Com isto, as possibilidades de atuação se expandem, tanto para os bibliotecários que buscam tal upgrade, como para outros profissionais da informação, tais como os gestores de informação. Desse modo, entende-se que os segmentos de atuação do profissional da informação ampliam-se proporcionalmente ao conjunto de competências, técnicas e conhecimentos que estes adquirem.

Ainda sobre a figura 6 , também é possível notar que há profissionais inseridos no segmento científico, indústrias, e serviços complementares, o que

\footnotetext{
${ }^{4}$ http://www2.portodigital.org/portodigital/Home/41774\%3B61399\%3B06\%3B0\%3B0.asp
} 
Tatyane Lucia Cruz. Fábio Mascarenhas e Silva. Leilah Santiago Bufrem. Natanael Vitor Sobral.

O perfil do gestor da informação: um estudo a partir dos egressos do curso de Gestão da Informação da UFPE

expressa uma boa diversidade nos locais de atuação, pressupondo uma pluralidade de competências e inserção mercadológica variada.

O sétimo item buscou identificar as disciplinas da graduação em GI que exercem maior ou menor influência nas rotinas de trabalho dos gestores da informação.

As disciplinas mais citadas como relevante e muito relevante (tabela 1), foram, respectivamente: recuperação da informação (93\%), análise de decisão (87\%), fontes de informação (87\%), usabilidade e arquitetura da informação (87\%), interação humano-sistema (87\%), sistemas de informação digital (87\%) e gestão de sistemas de informação (87\%).

Conforme afirmam Rubi, Euclides e Santos (2006), a informação se tornou um insumo indispensável, um recurso viabilizador de decisões nos mais diferentes campos. Porém, uma problemática relacionada à grande quantidade de informações é a filtragem e seleção de informações para um dado problema. A dificuldade de extrair informações precisas, atualizadas e com valor agregado é um grande desafio para os profissionais da informação, em especial, no contexto de tomada de decisão.

Deste modo, acredita-se que façam parte da rotina dos gestores atividades de mapeamento de fontes de informação, recuperação da informação em sistemas eletrônicos e análise de processos decisórios. A partir da análise das disciplinas indicadas como mais relevantes, destaca-se a ênfase nas disciplinas de TI nas práticas do gerenciamento informacional.

Tabela 1 - Relevância das disciplinas na rotina de trabalho dos egressos

\begin{tabular}{|c|l|l|}
\hline Recuperação da Informação & $93 \%$ & \\
\hline Análise de Decisão & $87 \%$ & \\
\hline Fontes de Informação & $87 \%$ & \\
\hline Usabilidade e Arquitetura da Informação & $87 \%$ & \\
\hline Interação Humano-Sistema & $87 \%$ & \\
\hline Sistemas de Informação Digital & $87 \%$ & \\
\hline Gestão de Sistemas de Informação & $87 \%$ & \\
\hline
\end{tabular}

Inf. Inf., Londrina, v. 22, n. 1, p. 150 - 184, jan./abr., 2017. http:www.uel.br/revistas/informacao/ 
Tatyane Lucia Cruz. Fábio Mascarenhas e Silva. Leilah Santiago Bufrem. Natanael Vitor Sobral.

O perfil do gestor da informação: um estudo a partir dos egressos do curso de Gestão da Informação da UFPE

\begin{tabular}{|c|c|c|}
\hline Sistemas de Apoio à Decisão & $85 \%$ & \\
\hline Estratégia das Organizações & $85 \%$ & \\
\hline Gestão da Informação nas Organizações & $85 \%$ & \\
\hline Sistemas de Informações Gerenciais & $85 \%$ & \\
\hline Indexação e Análise de assunto & $65 \%$ & \\
\hline Estruturas e Linguagens da Informação & $61 \%$ & \\
\hline Formatos e Protocolos de Sistemas & $57 \%$ & \\
\hline Representação Descritiva da Informação & $52 \%$ & \\
\hline Metodologia do Trabalho Científico & $52 \%$ & \\
\hline Pesquisa em Ciência da Informação & $52 \%$ & \\
\hline Sistemas de Categorização & $50 \%$ & \\
\hline Teoria Geral da Informação & $50 \%$ & \\
\hline Estudos Métricos da Informação & $50 \%$ & \\
\hline Fundamentos da Pesquisa Operacional & $43 \%$ & \\
\hline Memória e Conhecimento & $39 \%$ & \\
\hline
\end{tabular}

Fonte: Dados da pesquisa, 2017 - Elaboração Própria.

Em contrapartida, outras disciplinas foram inversamente indicadas por serem menos relevantes (tabela 1), dentre as quais se destacam: memória e conhecimento (39\%), fundamentos da pesquisa operacional $(43 \%)$, estudos métricos da informação (50\%), teoria geral da informação (50\%) e sistemas de categorização (50\%).

Infere-se que as atividades ligadas à memória se distanciam do cotidiano do gestor, tendo em vista que este segmento de atividade está mais vinculado ao contexto dos grandes acervos, museus e instituições de salvaguarda de documentos. Quanto à disciplina de pesquisa operacional, pelo fato desta ser eletiva e pouco ofertada ao longo do curso, não lhe foi atribuída muita importância, possivelmente pela pouca familiaridade dos discentes com o tema. 
Tatyane Lucia Cruz. Fábio Mascarenhas e Silva. Leilah Santiago Bufrem. Natanael Vitor Sobral.

O perfil do gestor da informação: um estudo a partir dos egressos do curso de Gestão da Informação da UFPE

A respeito da disciplina Estudos Métricos da Informação (EMI), percebese um forte viés acadêmico. Conforme afirmam Noronha e Maricato (2008), os EMI estão ligados à necessidade de se estabelecer indicadores específicos da ciência [...]. Desse modo, seu ensino nos cursos de $\mathrm{Cl}$ costuma ser centrado nos estudos da produtividade científica, por mais que se admita que os EMI extrapolem tais limites.

Quanto às demais disciplinas tidas como pouco relevantes, ressaltam-se aquelas vinculadas à pesquisa científica e aos aspectos teóricos, o que não surpreende pelo fato de não terem relações diretas com o mercado de trabalho.

Perguntou-se também o que os egressos pensavam sobre as competências de um gestor da informação contidas no PPC. Tal questão buscou identificar a coincidência das competências priorizadas no projeto do curso com as desejadas pelo mercado de trabalho. Os resultados podem ser visualizados na tabela 2 .

Tabela 2 - Relação entre as competências indicadas no PPC com as atividades de trabalho dos egressos do curso de GI/UFPE

\begin{tabular}{lcccc}
\hline \multicolumn{1}{c}{ Competências } & Nunca & Raramente & $\begin{array}{c}\text { Algumas } \\
\text { vezes }\end{array}$ & Sempre \\
\hline $\begin{array}{l}\text { Tecnologias para o incremento do } \\
\text { uso eficiente da informação }\end{array}$ & $6 \%$ & $17 \%$ & $20 \%$ & $\mathbf{5 7 \%}$ \\
$\begin{array}{l}\text { Gestão de recursos de informação } \\
\text { de diversas naturezas }\end{array}$ & $9 \%$ & $19 \%$ & $\mathbf{3 9 \%}$ & $33 \%$ \\
$\begin{array}{l}\text { Gerenciamento de unidades de } \\
\text { informação }\end{array}$ & $13 \%$ & $19 \%$ & $\mathbf{4 4 \%}$ & $24 \%$ \\
$\begin{array}{l}\text { Geração, análise, controle, acesso } \\
\text { e utilização da informação }\end{array}$ & $7 \%$ & $4 \%$ & $24 \%$ & $\mathbf{6 5 \%}$ \\
$\begin{array}{l}\text { Consultoria e prestação de serviços } \\
\text { de informação }\end{array}$ & $6 \%$ & $13 \%$ & $30 \%$ & $\mathbf{5 2 \%}$ \\
\hline \begin{tabular}{l} 
Fonte: Dados da pesquisa, 2017 - Elaboração Própria. \\
\hline
\end{tabular}
\end{tabular}

As competências mais indicadas como sempre necessárias foram: geração, análise, controle, acesso e utilização da informação (65\%), tecnologias para o incremento do uso eficiente da informação (57\%), consultoria e prestação de serviços de informação (52\%), gestão de recursos de informação de diversas naturezas (33\%), gerenciamento de unidades de informação (24\%).

Credita-se o alto desempenho da primeira ao fato de que ela concentra as atividades mais recorrentes nos processos de gestão da informação. A 
Tatyane Lucia Cruz. Fábio Mascarenhas e Silva. Leilah Santiago Bufrem. Natanael Vitor Sobral.

O perfil do gestor da informação: um estudo a partir dos egressos do curso de Gestão da Informação da UFPE

generalidade do tópico favorece contemplar atividades comuns em qualquer ambiente.

Reforça-se o destaque dado a TI, que coincide com os resultados identificados nas disciplinas mais relevantes, em particular as competências próprias ao incremento do uso eficiente da informação através das tecnologias. Outra atividade que chamou a atenção foi a consultoria e prestação de serviços em informação, evidenciando um estímulo aos dos gestores para empreenderem em seus próprios negócios.

Buscando verticalizar a discussão, apresenta-se a tabela 3 que traz as atitudes requeridas para o exercício dos trabalhos do profissional.

Tabela 3 - Atitudes requisitadas nas atividades de trabalho

\begin{tabular}{|c|c|c|c|c|}
\hline Atitudes & Nunca & Raramente & $\begin{array}{l}\text { Algumas } \\
\text { vezes }\end{array}$ & Sempre \\
\hline $\begin{array}{l}\text { Visão tecnológica (criação/gestão de } \\
\text { conteúdos) }\end{array}$ & $6 \%$ & $17 \%$ & $19 \%$ & $59 \%$ \\
\hline Capacidade de comunicação & $2 \%$ & $0 \%$ & $26 \%$ & $71 \%$ \\
\hline $\begin{array}{l}\text { Competências pedagógicas (ensino e } \\
\text { orientação) }\end{array}$ & $19 \%$ & $43 \%$ & $19 \%$ & $20 \%$ \\
\hline $\begin{array}{l}\text { Desenvolvimento de serviços de } \\
\text { informação }\end{array}$ & $7 \%$ & $33 \%$ & $24 \%$ & $35 \%$ \\
\hline $\begin{array}{l}\text { Representação e organização da } \\
\text { informação }\end{array}$ & $9 \%$ & $20 \%$ & $33 \%$ & $37 \%$ \\
\hline $\begin{array}{l}\text { Conhecimento do "universo" da } \\
\text { informação }\end{array}$ & $7 \%$ & $19 \%$ & $31 \%$ & $43 \%$ \\
\hline $\begin{array}{l}\begin{array}{l}\text { Aptidão para } \\
\text { colaborativa }\end{array}\end{array}$ & $2 \%$ & $4 \%$ & $31 \%$ & $63 \%$ \\
\hline Competências em gestão & $4 \%$ & $15 \%$ & $20 \%$ & $61 \%$ \\
\hline Curiosidade e espírito de inovação & $2 \%$ & $13 \%$ & $30 \%$ & $56 \%$ \\
\hline Adaptação a ambientes dinâmicos & $2 \%$ & $7 \%$ & $19 \%$ & $72 \%$ \\
\hline Visão estratégica e prospectiva & $6 \%$ & $15 \%$ & $33 \%$ & $46 \%$ \\
\hline
\end{tabular}

Fonte: Dados da pesquisa, 2017 - Elaboração Própria.

A comunicação $(71 \%)$ e a capacidade de adaptação a ambientes dinâmicos (72\%) foram as atitudes consideradas mais requeridas, bem como: 
Tatyane Lucia Cruz. Fábio Mascarenhas e Silva. Leilah Santiago Bufrem. Natanael Vitor Sobral.

O perfil do gestor da informação: um estudo a partir dos egressos do curso de Gestão da Informação da UFPE

aptidão para aprendizagem colaborativa (63\%); competências em gestão (61\%); visão tecnológica, incluindo-se nessa categoria criação/gestão de conteúdos (59\%) e curiosidade e espírito de inovação (56\%).

A alta incidência relacionada à capacidade de adaptação a ambientes dinâmicos reitera as previsões do relatório do Chatham House Forum para 2020, a partir de três cenários profissionais, cuja ênfase recai sobre as repercussões das estruturas e transformações tecnológicas na atuação profissional do gestor da informação (SPARROW, 1998). Em suma, para adaptar-se rapidamente aos ambientes dinâmicos, faz-se necessário que o gestor seja perspicaz o suficiente para compreender o ambiente no qual está inserido, percebendo em tempo hábil os sinais de mudanças, para que se antecipe às transformações.

Por fim, chama a atenção o baixo índice de gestores que consideram ser necessário pôr em prática as competências de ensino e orientação, sendo esta a competência mais citada como nunca requerida (19\%) e menos citada como sempre requerida (20\%). Espera-se que este quadro se reverta no futuro, pois a habilidade de transmitir ao próximo o que se sabe é um dos requisitos exigidos às lideranças, e deseja-se que os gestores se assumam como tal (líderes) em seus respectivos campos de atuação.

\section{CONCLUSÕES}

O objetivo deste estudo foi identificar as convergências e divergências entre a formação acadêmica do gestor da informação, egresso da UFPE, em relação à sua atuação profissional. Neste sentido, buscou-se conhecer como essa atuação vem ocorrendo no mercado de trabalho, podendo-se constatar, que de todos os profissionais participantes desta pesquisa (54), 85\% estão atualmente desenvolvendo atividades profissionais.

Enquanto limitação do estudo, destaca-se a importância de que todos os egressos tivessem respondido o questionário, embora essa ocorrência limitativa seja uma constante nesse tipo de instrumento. Tentar-se-á buscar essa completude em estudos futuros. 
Tatyane Lucia Cruz. Fábio Mascarenhas e Silva. Leilah Santiago Bufrem. Natanael Vitor Sobral.

O perfil do gestor da informação: um estudo a partir dos egressos do curso de Gestão da Informação da UFPE

Este estudo atingiu os seus objetivos à medida que aponta as relações entre a formação acadêmica do gestor da informação e suas práticas profissionais no mercado de trabalho, enfatizando as concepções explicitadas pelos egressos, construídas nos ambientes de troca entre a universidade, a prestação de serviços profissionais e a sociedade. Ainda, revela que é uma profissão em processo de consolidação e validação social, razão pela qual é mais que necessário o esforço dos gestores em contribuir com a divulgação da profissão.

\section{REFERÊNCIAS}

BRASIL. Agência Brasileira de Desenvolvimento Industrial. Formação e mercado de trabalho. Brasília: Governo Federal, 2012. 28 p. Disponível em: <http://www.brasilmaior.mdic.gov.br/images/data/201212/e4196555d9f62d9286 cccfaf5fd5e133.pdf>. Acesso em: 01 fev. 2016.

BOURDIEU, P. O campo científico. In: ORTIZ, R. (org.). Pierre Bourdieu: Sociologia. São Paulo: Ática, 1983, p. 122-155.

CARVALHAL, M. D. Os fundamentos do debate sobre a formação profissional. Revista Pegada Eletrônica (UNESP), Presidente Prudente, v. 3, n. 1, p.1-12, 2002. Disponível em: <http://revista.fct.unesp.br/index.php/pegada/article/view/799/822>. Acesso em: 14 mar. 2016.

DAVENPORT, T. Ecologia da informação: por que só a tecnologia não basta para o sucesso na era da informação. São Paulo: Futura, 1998.

DRUCKER, P. Sociedade Pós-Capitalista. 2. ed. Lisboa: Conjuntura Actual, 2015. 240 p. (Extra Coleção). Tradução de Maria Fernanda Jesuíno.

FERREIRA, A. B. H. Dicionário Aurélio. 5. ed. Curitiba: Positivo, 2010.

FERREIRA, D. T.; SANTOS, R. N. M. Profissional da informação: perfil de habilidades demandadas pelo mercado. Revista de Biblioteconomia de Brasília, Brasília, v. 23-24, n. 2, p. 147-160, 2000. Disponível em: <http://www.brapci.ufpr.br/brapci/index.php/article/view/0000001857>. Acesso em: 14 Mar. 2016.

FRASER-ARNOTT, M. Competencies for information specialists in emerging roles. Library Management, v. 38, n. 1, p. 65-76, 2017. 
Tatyane Lucia Cruz. Fábio Mascarenhas e Silva. Leilah Santiago Bufrem. Natanael Vitor Sobral.

O perfil do gestor da informação: um estudo a partir dos egressos do curso de Gestão da Informação da UFPE

FREIRE, I. M.; ARAUJO, V. M. R. H. de. A responsabilidade social da Ciência da informação. Transinformação, Campinas, v.11, n.1, p. 7-15, jan./abr., 1999.

GONDIM, S. M. G. A Sociedade da Informação, as Organizações Formais Educacionais, Valores e o Trabalho Docente: possíveis Inter-relações. Ética e Filosofia Política, Juiz de Fora, v. 3, n. 2, p.69-102, 1998.

GONZÁLEZ DE GOMEZ, M. N. A globalização e os novos espaços. Informare, Rio de Janeiro, v. 3, n. 2-3, jan. 1997.

KUENZER, A. A Pedagogia da Fábrica: as relações de produção e a educação do trabalhador. São Paulo: Cortez, 1985.

Ensino médio e profissional: as políticas do estado neoliberal. São Paulo: Cortez, 1988.

Competência como práxis: os dilemas da relação entre teoria e prática na educação dos trabalhadores. Boletim Técnico do SENAC, Rio de Janeiro, v. 29 , n.1, p. 17-27, jan./abr. 2003.

LASTRES, H. M. M; FERRAZ, J. Economia da informação, do conhecimento e do aprendizado. In: LASTRES, H M M; ALBAGLI, S (Ed.). Informação e Globalização na Era do Conhecimento. Rio de Janeiro: Campus, 1999. Cap. 1. p. 27-57. Disponível em: <http://www.uff.br/ppgci/editais/saritalivro>. Acesso em: 13 mar. 2016.

LE COADIC, Y.-F. A ciência da informação. 2. ed. Brasília: Briquet de Lemos, 2004.

LOURENÇO, G. M. Economia paranaense: novos cenários. Análise Conjuntural, Curitiba, v.21, n.1-2, p.3-12, jan./fev. 1999.

MARCHIORI, P, Z. A ciência e a gestão da informação: compatibilidades no espaço profissional. Ciência da Informação, Brasília, v. 31, n. 2, out. 2002. Disponível em: <http://revista.ibict.br/index.php/ciinf/article/view/159>. Acesso em: 13 Mar. 2016.

ORENGO, M.; ABREU, F. A Responsabilidade social e o seu impacto estratégico na gestão dos projetos do parque das nações (Lisboa) e do Porto Digital (Recife). 2009. 17 f. Monografia (Especialização) - Curso de Gestão Empresarial, Fundação Getúlio Vargas, Santa Maria, 2009. Disponível em: <http://www.conferp.org.br/wp-content/uploads/2009/07/tcclisboa.pdf>. Acesso em: 14 jan. 2016. 
Tatyane Lucia Cruz. Fábio Mascarenhas e Silva. Leilah Santiago Bufrem. Natanael Vitor Sobral.

O perfil do gestor da informação: um estudo a partir dos egressos do curso de Gestão da Informação da UFPE

NORONHA, D. P.; MARICATO, J. de. M. Estudos métricos da informação:

primeiras aproximações. Encontros Bibli: revista eletrônica de biblioteconomia e ciência da informação, Florianópolis, p. 116-128, abr. 2008. Disponível em: $<$ https://periodicos.ufsc.br/index.php/eb/article/view/15182924.2008v13nesp1p1 16>. Acesso em: 14 mar. 2016.

PORTO DIGITAL. O que é o Porto Digital. 2016. Disponível em: $<$ http://www.portodigital.org/parque/o-que-e-o-porto-digital\#submenuempresas >. Acesso em: 02 fev. 2016.

RUBI, M. P.; EUCLIDES, M. L.; SANTOS, J. C. dos. Profissional da informação: aspectos de formação, atuação profissional e marketing para o mercado de trabalho. Informação \& Sociedade: Estudos, João Pessoa, v. 16, n. 1, p. 7989, 2006. Disponível em:

$<$ http://www.ies.ufpb.br/ojs/index.php/ies/article/view/443>. Acesso em: 14 mar. 2016.

SAVIANI, D. O trabalho como princípio educativo frente as novas tecnologias. In: FERRETTI, C J et al (Org.). Novas tecnologias, trabalho e educação: um debate multidisciplinar. 9. ed. Petrópolis: Vozes, 2003. p. 151-168.

SEVERINO, A. J. A busca do sentido da formação humana: tarefa da Filosofia da Educação. Educação e Pesquisa, São Paulo, v. 32, n. 3, p. 619-634, dez. 2006. Disponível em: <http://www.revistas.usp.br/ep/article/view/28030>. Acesso em: 14 mar. 2016.

SILVA, E. L. da; CUNHA, M. V. da. A formação profissional no século XXI: desafios e dilemas. Ci. Inf., Brasília, v. 31, n. 3, p. 77-82, set. 2002. Disponível em: <http://www.scielo.br/scielo.php?script=sci arttext\&pid=S0100$19652002000300008 \&$ Ing=en\&nrm=iso>. Acesso em 14 mar. 2016.

SPARROW, O.. Open Horizons: three Scenarios for 2020 (the 1998 Report from the Chatham House Forum) Multimedia CD, dez. 1998.

UNIVERSIDADE FEDERAL DE PERNAMBUCO. Departamento de Ciência da Informação. Projeto político pedagógico do curso de graduação em Gestão da Informação. Recife, 2012. 69 p.

ZAPAROLLI, I. Quality control of vocational higher education and training in Brazil: the relationship among universities, ministry of education, professional representative institutions and labour market. Semina: Ciências Sociais e Humanas, Londrina, v. 25, p.75-88, set. 2004. Disponível em: $<$ http://www.uel.br/revistas/uel/index.php/seminasoc/article/download/3814/307 2>. Acesso em: 14 mar. 2016. 
Tatyane Lucia Cruz. Fábio Mascarenhas e Silva. Leilah Santiago Bufrem. Natanael Vitor Sobral.

O perfil do gestor da informação: um estudo a partir dos egressos do curso de Gestão da Informação da UFPE

\title{
Title
}

The information manager profile: a study from the graduates of the course of the UFPE information management

\begin{abstract}
:
Introduction: With the recent social and economic changes come new possibilities for performance of information professionals. In this context, it is part of the Manager of information, which can contribute to finding solutions to the major challenges related to the collection, processing and use of information. Objective: To study the relationship between academic Manager information egress from UFPE, and your professional performance. Methodology: a) literature review; b) mapping of the graduates; c) preparation of the questionnaire; d) provision of the questionnaire; e) tabulation and data formatting; f) data analysis. Results: 54 of the 71 graduates responded to the questionnaire $(76 \%)$, a percentage considered satisfactory. It highlights the following results: $85 \%$ of graduates are developing professional activities; $56 \%$ of the employed are working in activities related to the field of Information Management; professional business segments are different, especially the service sector (34\%). In the organizational pyramid, it was found that the level of activity is most representative operating $(43 \%)$. On the issue of disciplines, it drew attention that managers have a greater need to employ the knowledge related to Information Technology. Conclusions: We emphasize the importance of today's information manager, emphasizing the need to improve this new profession in relation to the demands of society.
\end{abstract}

Keywords: Professional Practice. Formation; Manager of information. Information management. UFPE.

\section{Titulo}

Perfil del gestor de información: un estudio de los graduados del curso de gestión de la información UFPE

\section{Resumen:}

Introducción: Los recientes cambios sociales y económicos abren nuevas posibilidades para el desempeño de los profesionales de la información. En este contexto, el Gestor de información puede contribuir a la búsqueda de soluciones a los principales retos relacionados con la recolección, procesamiento y uso de la información. Objetivo: Estudiar la relación entre el Gestor de información científica, su desempeño profesional y los resultados de la UFPE. Metodología: a) revisión de la literatura; b) selección de los graduados; c) elaboración del cuestionario; d) envío del cuestionario; e) tabulación y formato de datos; f) análisis de datos. Resultados: 54 de los 71 graduados respondieron al cuestionario (76\%), un porcentaje considerado satisfactorio. Se destacan los siguientes resultados: el $85 \%$ de los graduados está desarrollando actividades profesionales; el $56 \%$ de los empleados trabaja en actividades relacionadas con el campo de la gestión de información; los segmentos de negocios profesionales se diferencian unos de otros, especialmente el sector de servicios (34\%). Se determinó que el nivel de actividad operativo es el más representativo en la pirámide de la organización (43\%). En cuanto a las disciplinas, se observa que los gerentes tienen una mayor necesidad de conocimiento vinculado a las 
Tatyane Lucia Cruz. Fábio Mascarenhas e Silva. Leilah Santiago Bufrem. Natanael Vitor Sobral.

O perfil do gestor da informação: um estudo a partir dos egressos do curso de Gestão da Informação da UFPE

tecnologías de información. Conclusiones: Se destaca la importancia del gestor de información en la actualidad y se insiste en la necesidad de mejorar esta nueva profesión para satisfacer las demandas de la sociedad.

Palabras clave: Práctica Profesional. Formación. Gestor de Información. Gestión de Información. UFPE.

\section{Apêndice A}

Mapeamento do Perfil do Gestor da informação

*Obrigatório

Nome: *

\section{1) Atualmente você está: *} da informação

$\begin{array}{ll}\circ & \text { Atuando em outra função } \\ \circ & \text { Não estou trabalhando } \\ \circ & \text { Estou somente estudando }\end{array}$

2) O segmento da instituição que você atua é:

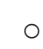

0

$\bigcirc$

○

$\bigcirc$ descontaminação

○

$\bigcirc$

$\bigcirc$

○

$\bigcirc$

○

○

○

$\bigcirc$

Agricultura, pecuária, produção florestal, pesca e aqüicultura

Indústrias extrativas

Indústrias de transformação

Eletricidade e gás

Água, esgoto, atividades de gestão de resíduos e

Comércio; reparação de veículos automotores e motocicletas

Transporte, armazenagem e correio

Alojamento e alimentação

Informação e comunicação

Atividades financeiras, de seguros e serviços relacionados

Atividades imobiliárias

Atividades profissionais, científicas e técnicas

Atividades administrativas e serviços complementares

Administração pública, defesa e seguridade social 
Tatyane Lucia Cruz. Fábio Mascarenhas e Silva. Leilah Santiago Bufrem. Natanael Vitor Sobral.

O perfil do gestor da informação: um estudo a partir dos egressos do curso de Gestão da Informação da UFPE

$\begin{array}{cl}\circ & \text { Saúde humana e serviços sociais } \\ \circ & \text { Artes, cultura, esporte e recreação } \\ \circ & \text { Serviços domésticos } \\ \circ & \text { Organismos internacionais e outras instituições } \\ & \text { extraterritoriais } \\ \circ & \text { Outras atividades de serviços }\end{array}$

3) Você atua: *

- $\quad$ Como profissional dentro da Região Metropolitana do Recife

- Como profissional, mas não na Região Metropolitana do

Recife

- Não atuo profissionalmente

4) Em qual esfera organizacional você se encontra lotado? *

\begin{tabular}{ll}
$\circ$ & Operacional \\
$\circ$ & Gerencial \\
$\circ$ & Estratégica \\
$\circ$ & Executiva (diretorias) \\
$\circ$ & Outra \\
\hline & Não estou atuando profissionalmente
\end{tabular}

5) Qual o nome do cargo que ocupa? *

6) Possui outra formação/especialização?

\begin{tabular}{|c|c|c|}
\hline & $\Gamma$ & Especialização \\
\hline & г & Graduação \\
\hline & $\Gamma$ & Mestrado \\
\hline & $\Gamma$ & Doutorado \\
\hline & $\Gamma$ & Técnico/tecnólogo \\
\hline & г & Não \\
\hline
\end{tabular}

7) Como você avalia a relevância das disciplinas do curso de Gestão da Informação com relação as atividades que você desenvolve no trabalho ou nos estudos. *

Muito relevante Relevante $\begin{gathered}\text { Pouco } \\ \text { relevante Nada relevante }\end{gathered}$


Tatyane Lucia Cruz. Fábio Mascarenhas e Silva. Leilah Santiago Bufrem. Natanael Vitor Sobral.

O perfil do gestor da informação: um estudo a partir dos egressos do curso de Gestão da Informação da UFPE

Muito relevante Relevante $\begin{gathered}\text { Pouco } \\ \text { relevante }\end{gathered}$

Fundamentos

da Org. Inform.

Introdução à

Org. da

Informação

Indexação e

Análise de

Assunto

Recuperação

da Informação

Representação

Descritiva da

Informação

Recursos para

Org. da

Informação

Gestão

Documental

Práticas em

Org. da

Informação

Sistemas de

Categorização

Preservação

Digital

Memória e

Conhecimento

Teoria Geral da

Informação

Política de

Informação

Inf. Inf., Londrina, v. 22, n. 1, p. 150 - 184, jan./abr., 2017.

http:www.uel.br/revistas/informacao/ 
Tatyane Lucia Cruz. Fábio Mascarenhas e Silva. Leilah Santiago Bufrem. Natanael Vitor Sobral.

O perfil do gestor da informação: um estudo a partir dos egressos do curso de Gestão da Informação da UFPE

Muito relevante Relevante $\begin{gathered}\text { Pouco } \\ \text { relevante Nada relevante }\end{gathered}$

Economia da

Informação

Direito da

Informação

Uso Social da

Informação

Produção e uso

da Informação

Fund. da

Gestão do

Conhecimento

Análise de

Decisão

Gestão da

Qualidade Total

Sistemas de

Apoio à

Decisão

Fund.da Gestão

da Informação

Estratégia das

Organizações

Estratégias das

Operações

Processos

Organizacionais

Gestão da

Informação nas

Organizações

Práticas em

Gestão da

Informação

Inf. Inf., Londrina, v. 22, n. 1, p. 150 - 184, jan./abr., 2017.

http:www.uel.br/revistas/informacao/ 
Tatyane Lucia Cruz. Fábio Mascarenhas e Silva. Leilah Santiago Bufrem. Natanael Vitor Sobral.

O perfil do gestor da informação: um estudo a partir dos egressos do curso de Gestão da Informação da UFPE

Muito relevante Relevante $\begin{gathered}\text { Pouco } \\ \text { relevante }\end{gathered}$

Fontes de

Informação

Estudos

Métricos da

Informação

Base de Dados

Especializados

Usabilidade e

Arquitetura da

Informação

Interação

Humano-

Sistema

Intr. aos

Recursos de

Progr. e Sist.

Oper.

Sistemas de

Informação

Digital

Sistemas de

Informações

Gerenciais

Sistemas de

Informações

Executivas

Projeto de

Sistemas de

Informação

Gestão de

Sistemas de

Informação

Formatos e Protocolos de

Inf. Inf., Londrina, v. 22, n. 1, p. 150 - 184, jan./abr., 2017. http:www.uel.br/revistas/informacao/ 
Tatyane Lucia Cruz. Fábio Mascarenhas e Silva. Leilah Santiago Bufrem. Natanael Vitor Sobral.

O perfil do gestor da informação: um estudo a partir dos egressos do curso de Gestão da Informação da UFPE

$\begin{array}{llll}\text { Muito relevante Relevante } & \begin{array}{c}\text { Pouco } \\ \text { relevante }\end{array} & \text { Nada relevante } \\ \text { Sistemas } & & \end{array}$

\section{Estruturas e}

linguagens da

informação

Fundamentos

da Pesquisa

Operacional

Metodologia do

Trabalho

Científico

Pesquisa em

Ciência da

Informação

8) Com relação às competências desempenhadas em seu trabalho, elas são necessárias: *

Sempre Algumas vezes Raramente Nunca

\section{Consultoria e prestação de serviços de informação \\ Geração, análise, controle, acesso e utilização da informação \\ Gerenciamento de unidades de informação \\ Gestão de recursos de informação de diversas naturezas}


Tatyane Lucia Cruz. Fábio Mascarenhas e Silva. Leilah Santiago Bufrem. Natanael Vitor Sobral.

O perfil do gestor da informação: um estudo a partir dos egressos do curso de Gestão da Informação da UFPE

Sempre Algumas vezes Raramente Nunca
Tecnologias
para o
incremento do
uso eficiente
da informação

9) As atitudes a seguir se assemelham com a sua rotina de trabalho? *

Sempre $\begin{gathered}\text { Algumas } \\ \text { vezes }\end{gathered}$ Raramente Nunca

Visão estratégica e

prospectiva

Versatilidade e

capacidade de adaptação

a ambientes dinâmicos

Curiosidade e espírito de

inovação

Competências em gestão

Aptidão para o trabalho e para aprendizagem

colaborativa

Conhecimento e compreensão do "universo" da informação/documentação

Representação e organização da informação

Concepção e desenvolvimento de serviços de informação

Competências pedagógicas, de ensino e orientação

Capacidade de comunicação 
Tatyane Lucia Cruz. Fábio Mascarenhas e Silva. Leilah Santiago Bufrem. Natanael Vitor Sobral.

O perfil do gestor da informação: um estudo a partir dos egressos do curso de Gestão da Informação da UFPE

Sempre $\begin{gathered}\text { Algumas } \\ \text { vezes }\end{gathered}$ Raramente Nunca

Visão atualizada das inovações tecnológicas destinadas à criação e gestão de conteúdos

10) Das habilidades a seguir, marque aquelas requeridas e/ou executadas por você em seu trabalho? *

(pode marcar quantas alternativas desejar)

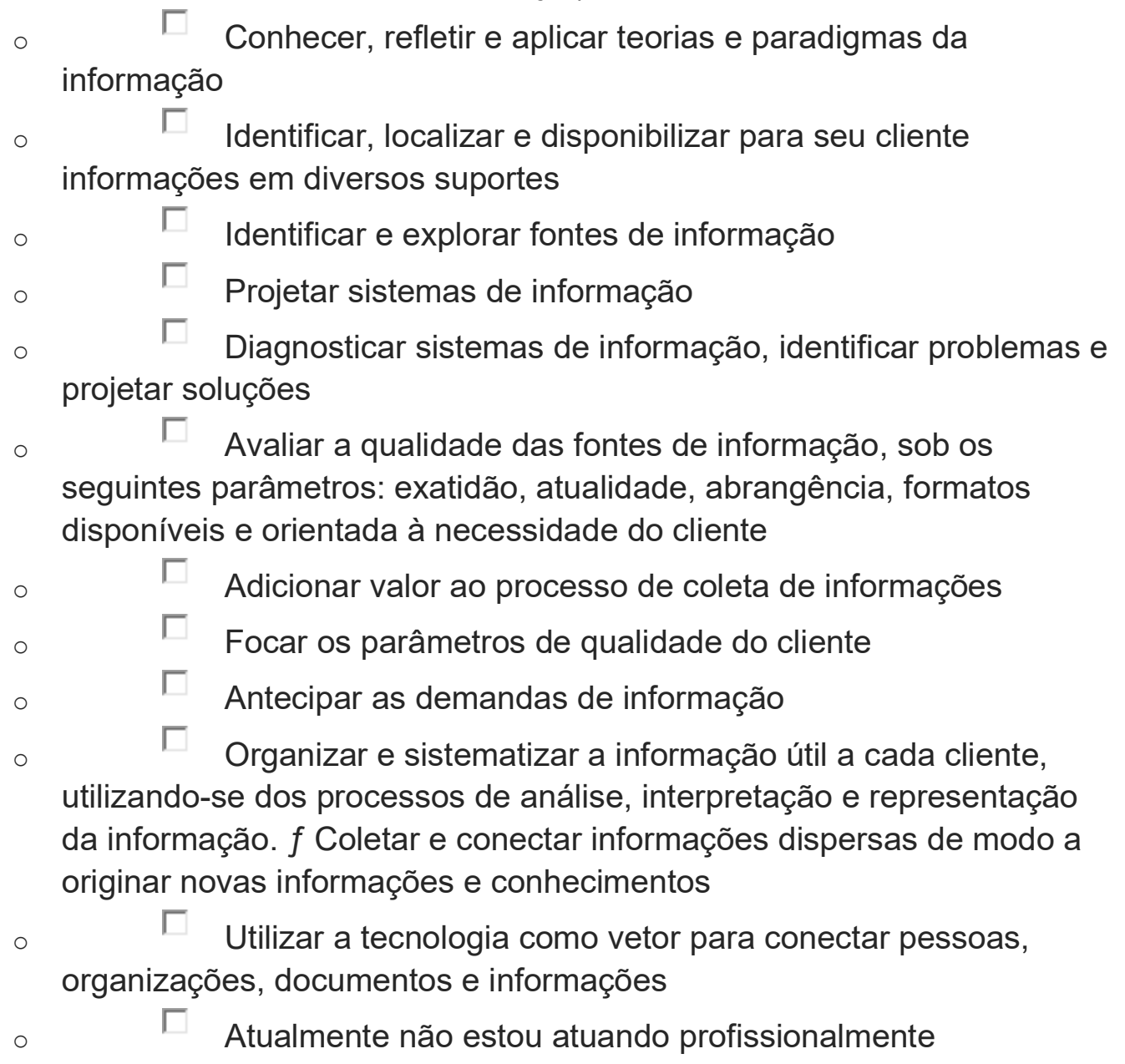

Recebido: 12.02 .2016

Aceito: 25.03.2017 